\title{
Volunteers and Ex-Volunteers: Paths to Civic Engagement Through Volunteerism
}

\section{Voluntarios y Ex Voluntarios: Perfiles de Participación Ciudadana a Través del Voluntariado}

\author{
Elena Marta, Maura Pozzi and Daniela Marzana \\ Università Cattolica del Sacro Cuore di Milano
}

\begin{abstract}
The study described is part of a broader longitudinal and multi-methodological research project aimed at investigating volunteerism in young people, in order to understand the reasons for the initial choice to volunteer but, more specifically, the reasons to sustain or quit voluntary involvement, as well as the effects of volunteerism. Eighteen volunteers and 18 ex-volunteers, $50 \%$ male and $50 \%$ female, aged between 22 and 29 years old, from 2 regions in northern Italy (Lombardy and Emilia Romagna) participated in in-depth interviews. The paper-and-pencil analysis of the interview pointed to the emergence of several core categories: motivations to volunteer, relations within the organization, influence of family, and effects of volunteerism, especially as related to the process of identity and citizenship construction. On the basis of these categories, 4 typologies were identified: 2 with respect to volunteers (producers of active citizenship and volunteers for personal necessity) and 2 related specifically to ex-volunteers (ex-volunteers witnesses for solidarity and active citizenship and ex-volunteers by chance).
\end{abstract}

Keywords: volunteerism, young people, civic engagement

El estudio descrito es parte de un proyecto de investigación longitudinal y multi-metodológico más amplio sobre el voluntariado juvenil, realizado con el propósito de entender las razones que tuvieron los jóvenes para elegir el voluntariado y, específicamente, las razones para mantener o abandonar el compromiso, así como los efectos de dicho voluntariado. Participaron en entrevistas en profundidad 18 voluntarios y 18 ex-voluntarios, $50 \%$ hombres y $50 \%$ mujeres, entre 22 y 29 años de edad, de 2 regiones del norte de Italia (Lombardía y Emilia Romagna). El análisis de la entrevista de lápiz y papel permitió trazar varias categorías centrales: las motivaciones al voluntariado, las relaciones dentro de la organización, la influencia de la familia y los efectos del propio voluntariado, especialmente en relación con el proceso de construcción de identidad y ciudadanía. A partir de estas categorías fueron identificadas 4 tipologías: 2 respecto de los voluntarios (voluntarios productores de ciudadanía activa y voluntarios por necesidad personal) y 2 respecto de los ex voluntarios (ex voluntarios testigos de solidaridad y ciudadanía activa y ex voluntarios por azar).

Palabras clave: voluntariado, jóvenes adultos, compromiso cívico

Volunteerism has been defined as a specific type of sustained, planned, and prosocial behavior that benefits others and occurs within an organizational setting (Omoto \& Snyder, 1995; Penner, 2002; Snyder \& Omoto, 2000). Volunteers are generally defined as:

people [who] often actively seek out opportunities to help others; may deliberate for considerable amounts of time about whether to volunteer, the extent of their involvement, and the degree to which particular acti- vities fit with their own personal needs; and may make a commitment to an ongoing helping relationship that may extend over a considerable period of time and that may entail considerable personal costs of time, energy, and opportunity (Clary et al., 1998, p. 1517)

Research into volunteerism has focused on identifying relational paths between variables which attempt to determine the predictors of intention to continue or quit vol-

Elena Marta, Maura Pozzi, and Daniela Marzana, Psychology Department, Faculty of Psychology, Università Cattolica del Sacro Cuore di Milano, Italy.

Correspondence concerning this article should be addressed to Elena Marta, Psychology Department, Università Cattolica del Sacro Cuore di Milano, Largo Fra Agostino Gemelli, 1, 20123 Milano, Italia. E-mail: elena. marta@unicatt.it 
untary activity (Callero, Howard, \& Piliavin, 1987; Chacón, Vecina, \& Davila, 2006; Marta \& Pozzi, 2007; Omoto \& Snyder, 1995; Pozzi \& Marta, 2006).

In the light of this, in the present study we attempted to explain young adult volunteerism by addressing the following general questions: (a) What are the paths taken by and the motivations of young people who are involved in the experience of volunteerism and what induces a young person to sustain involvement over time or to quit it? and (b) What are the effects of volunteerism in terms of formation of identity and active citizenship in those who have decided to either continue or quit voluntary activity?

The aims of this research were specifically to:

1. Investigate personal and family paths and motivations that lead a young person to choose and then sustain involvement over time or interrupt it

2. Evaluate the role of the organization in the choice to remain committed to volunteerism or to quit voluntary activity

3. Verify the effects of volunteerism, especially in terms of volunteer identity construction and civic engagement.

In the first part of this article we provide an overview of the principal studies on volunteerism with particular focus on the areas that have been most extensively analyzed: motivations, relationships with organizations, identity, and family. These are the variables that the principal models on volunteerism -Omoto and Snyder's (1995) volunteer process model and Callero et al.'s (1987) role identity model- have identified as being crucial for understanding volunteerism and which, until now, have never been considered conjointly. In the second part, we present a study on volunteerism.

\section{The Principal Variables That Explicate the Phenomenon of Volunteerism}

\section{Motivations}

Beyond drawing distinctions between different motivations, the literature today is raising questions about the real impact of motivations (as well as about exactly which motivations are at work) on, first of all, the choice and length of involvement in volunteerism, and, second, about which relationships exist between this variable and others which may serve to better explain the multifaceted phenomenon of volunteerism.

In numerous studies Omoto and Snyder (1995, 2002; Snyder \& Omoto, 2000) have highlighted the direct impact of motivations on the length of voluntary service. According to their model (volunteer process model), the more a subject is motivated the longer his or her commitment to voluntary activity will last. The American researchers assert, moreover, that the motivations that influence the decision to become a volunteer are generally different from those that work to maintain commitment over time.

The literature demonstrates a predictive, direct effect of volunteerism motivations on length of service. Omoto and Snyder (1995) found that other-focused motivations are related to beginning voluntary service and that self-oriented motivations predicted the length of time in voluntary service. However, recent research has shown that motivations and the volunteer's involvement bond are more complex. Subsequent research has not confirmed a significant direct correlation between motivation and length of service (Chacón, Menard, Sanz, $\&$ Vecina, 1998). The research shows an indirect effect due to the volunteer's experience in the organization. Satisfaction and integration with the group were assumed as mediating variables (Barbaranelli, Caprara, Capanna, \& Imbimbo, 1999).

In other words, following Omoto and Snyder's volunteer process model (1995), it seems that a strong motivational push is not enough in itself to maintain sustained involvement, but a favourable organizational context is needed to satisfy personal and social functions that are at the heart of motivations. This means an organizational context that "recognizes and plans for the specific needs of volunteers motivated by esteem enhancement and personal development (...) and that adjusts its expectations for volunteers and their longevity of service" (Omoto \& Snyder, 1993, pp. 172-173).

Recently, Grube and Piliavin (2000) have advanced the hypothesis of a possible 
connection between motivations and role identities, inviting more research to probe this link. In particular, they hypothesize a relationship between role identity and ego-defense, values, and social motivations, with reciprocal reinforcement of these two constructs in promoting sustained involvement in voluntary activity over time.

Clary, Snyder, and Worth (2003) have conducted an interesting study with volunteer organizations, investigating the match between volunteers' motivations and organizations' needs. The authors focused on several elements, called facilitators, that, in their opinion, may promote a favourable match between a volunteer's motivations and the organization's needs, and other elements called obstacles, that may instead block a favourable match. The authors claim that facilitators and obstacles may lead to the onset of positive or negative emotions during the volunteer's experience. These, in turn, determine whether he or she remains in or leaves the organization. The authors identified facilitators and obstacles based on six functions in terms of volunteer involvement. Facilitators were defined as all the opportunities offered by organizations to respond to needs underpinning involvement: self-protection, development of social relations, career, understanding, selfenhancement, and values. Obstacles were defined as all those elements within the organization that prevent the satisfaction of the motivations which induced subjects to volunteer. Echoing results in literature on organizational psychology (Bruscaglioni, 1997), the study demonstrated the importance of matching volunteer motivations with their organizational environment (Clary et al., 2003). The operative outcomes of this study are clear: Identifying adequate matching between volunteers and organizations can make it possible to develop adequate practices of volunteer recruitment and training.

\section{Organization}

The importance of organizational variables has been confirmed by numerous studies in literature. In a study of a sample of young adult volunteers, Chacón et al.
(2006) hypothesized that the intention to sustain volunteer activity in the short term (six months), middle term (one year), or long term (two years) has different predictive variables. While satisfaction seems to be the best predictor of intention for the short term, organizational commitment seems to be the best predictor for the middle term and role identity for the long term. In other words, at the onset of volunteering one stays connected to the organization due to feelings of satisfaction derived from the activity itself, while simultaneously feeling satisfied with oneself in terms of self-efficacy. With the passage of time, the variables that come into play are strictly organizational in nature, in that one must feel committed and connected to the organization. In the long run, only the perception of being a volunteer -that one's identity is that of a volunteer- has an impact on the intention to continue and on the actual length of service.

Omoto and Snyder (1995) revealed that the number and quality of relationships that volunteers form during their period of service affect their satisfaction and their integration in the organization. Volunteers who are more satisfied with their volunteering tend to have greater intention to continue with it and to stay with the organization for a longer time.

\section{Identity}

Volunteerism contributes to the formation of social identity and community identity. As defined by Puddifoot (1996), like other types of identity, whether social, gender, ethnic, or otherwise, it "determines inclusion, exclusion, and belonging to a group" (p. 328).

In volunteerism social relationships are generated and become meaningful. Processes of socialization and especially adult identity construction are engendered and developed. The exchange of ideas and experiences promotes inner growth and contributes to self-definition.

The theme of identity is central to Piliavin and colleagues' theoretical framework (Piliavin, Grube, \& Callero, 2002; Piliavin \& Siegl, 2007): In their opinion, behaviours often satisfy a symbolic function 
of confirmation expression of the person's personal and social identity.

When a role is associated with a position inside a relational network, it is internalized and assumed as a component of the self (McCall \& Simmons, 1978). For example, a person develops a role identity of volunteer when he or she enacts the passage from action to self-definition; that is, when an understanding is reached that one's involvement in volunteering has taken on a role defined in the context of social relations. Volunteer role identity is thus connected to one's activity carried out as a volunteer rather than to the fact of belonging to a particular group of volunteers. For the individual, being a volunteer goes beyond simply doing volunteer work and becomes part of his or her identity. When involvement in volunteerism is continued for a lengthy period of time, volunteer role identity is consolidated. A virtuous circle is thus set in motion that leads to the continuation over time of volunteer involvement, since the individual tends to enact behaviours coherent with his or her role.

\section{Family}

Several recent studies on volunteerism (Wilson, 2005) have revealed that volunteerism is a phenomenon that involves one's entire family of origin. Its influence on young volunteers has only recently been investigated. It is well known that educational practices and family experiences can contribute to inhibiting or developing individual prosocial behavior (Eisenberg \& Fabes, 1998). Several studies have indicated that the quality of family relationships is important in predicting sustained service participation (Clary \& Miller, 1986; Hart \& Fegley, 1995). Fletcher, Elder, and Mekos (2000), by means of longitudinal research, verified the complex relation between educational styles, parenting (support and warmth), and educational practices (parental reinforcement and modeling) in predicting children's participation in voluntary activities. Research highlights the support-oriented parental style as an active instrument in predicting children's involvement independently of their parents' social commitment.
Our research has revealed that parental support is a good predictor of prosocial behavior and commitment in voluntary organizations (Boccacin \& Marta, 2003; Marta \& Scabini, 2003).

Family influence is rooted in its primary task, which is to care for offspring and, through them, for future generations, i.e. generativity (Erikson, 1968). According to Erikson, generativity "is primarily the concern in establishing and guiding the next generation" (1968, p. 267). Starting from that concept, McAdams and de St. Aubin (1992) developed generativity as the individual's ability to care for the next generation. According to a relational-symbolic approach (Scabini \& Cigoli, 2000), generativity is relational at its core. This is because of its relational source; in fact, it expresses itself through the relationship with the other.

Generativity is always altruistic, both when it is expressed as care or concern for the other, as well as in its narcissistic desire to leave surviving evidence of the self after one's death.

There is little in the literature showing this construct as related to volunteerism, in particular, with respect to young adult voluntary service (Singer, King, Green, \& Barr, 2002; Snyder \& Clary, 2003). However, generativity is a feature of a psychological aspect that we believe to be useful in understanding differences between volunteers and ex-volunteers.

\section{Method}

\section{Participants}

The sample was drawn from a longitudinal data set constructed as part of a large project on young adult volunteers involving both a quantitative and a qualitative component.

We recruited the participants of the present study among subjects who participated in the first wave of the longitudinal study in 2000 (Time 1) and who completed the third round of data collection in 2004 (Time 3). At Time 1 of the study there were 461 young volunteers, aged 21-29 years, residents in Lombardy and Emilia Romagna. 
We assumed that the voluntary service organizations are distributed proportionally with respect to population density. Three volunteers were randomly selected from each organization. The volunteers were engaged in voluntary service organizations working with minors for a minimum of three hours a week or at least twenty days a year. Gender distribution reproduces the present situation in the examined territories as regards the age of interest: male (45.8\%) and female (54.2\%).

On the basis of the Time 2 findings (in 2001), in which volunteers were asked to state their current position with respect to volunteerism (whether they were continuing or had quit service), we randomly selected 40 young volunteers at Time 3: 20 were continuing their involvement and 20 had quit involvement. We contacted these 40 young adults telephonically, asking them about their willingness to conclude the research process with a meeting in which an in-depth interview would be conducted. Thirty six young adults decided to participate in the study, three declined, and one accepted but did not show up to the interview.

Therefore, the participants in the qualitative study that we describe in this article were 36 young volunteers: 18 were continuing their involvement and were aged 22-29 years $(M=25.3, S D=1.8)$ and 18 had quit involvement and were aged $23-27$ years $(M$ $=25.5, S D=1.3$ ). Both those who were continuing the activity and those who had quit it were equally distributed on the basis of gender: $50 \%$ were female, $50 \%$ were male.

At Time 1 (2000), those who were continuing voluntary service stated that they dedicated about three hours a week to it ( $M$ $=3.1, S D=1.3$ ) in contrast to two hours for those who had quit it $(M=2.0, S D=1.1)$. Moreover, those who were continuing voluntary service stated that they have been doing so for about 3.4 years $(M=3.4, S D=$ 1.4), while those who had ended it, for 3.8 years $(M=3.8, S D=1.3)$.

In both groups the majority had a high school diploma (89\% of those who were continuing voluntary service and $81 \%$ of those who had quit). None were married. As for working status, $47.1 \%$ of those who were continuing were employed, while another
$47 \%$ were students $(5.9 \%$ stated they were doing something else). Among those who had ended voluntary service, $72.7 \%$ were university students and $27.3 \%$ were employed. Participants enjoyed a medium to high socioeconomic status.

\section{Instrument}

The instrument we utilized was a faceto-face in-depth interview based on a flexible scheme, or trace, that gives most of space to the interviewee, thus encouraging the emergence of the participants' points of view without placing rigid constraints with respect to the moment, sequence, or manner in which topics are taken up. This form of interview seeks to instill a relationship of trust with the interviewee and a desire to share, as much as possible, his or her psychological and social world.

The areas under consideration in the interview were related to the interviewees' childhood and family relations, the choice to become involved in volunteerism and the resulting experience, future plans, and the effects of volunteerism on one's life.

The investigative areas that we considered in the interviews, which correspond to the trace stimuli, were:

1. The re-evocation of childhood: Memories connected to the latent phase (811 years) concerning family norms and habits, and life experiences with one's family of origin, parents, and other significant figures, with the aim of investigating the family matrix and the quality of current relationships.

2. The maturation path that led to the choice to become a volunteer and to belong to a particular organized group, with the aim of probing personal motivations and the intentionality/randomness of the choice.

3. The experience of volunteerism from the beginning to the present, with the aim of verifying the initial impact of the subject with the organization, his or her involvement and assumption of roles, any training provided, satisfaction, social integration, the importance of being a volunteer in one's life, and changes deriving from the experience. 
4. The relationship with other volunteers and organizational operatives, with the aim of verifying the development of a sense of belonging and the expansion of one's friendship network.

5. The relationship with beneficiaries, with the aim of shedding light on the difficulties and problems encountered in relationships with "underprivileged" people, gratification, or feelings of inadequacy and impotence.

6. The future predictions for voluntary service, with the aim of discerning a desire to continue to be active over time or a future intention to interrupt activity or to take it up again.

7. The effects of volunteer experience, both for those who continue to be active and for those who interrupt, with particular attention accorded to repercussions on personal and civic identity.

We recorded and transcribed in their entirely the one-hour interviews.

\section{Procedure}

In the large longitudinal project, structured face-to-face interviews were conducted with the volunteers in their organization. When the interview was completed, participants filled out a self-administered paperand-pencil questionnaire. The respondents were informed that all information was confidential and subpoena protected and their consent was requested for the second data collection (Time 2) and in the second data collection for the third collection (Time 3).

In the qualitative study we describe here, we asked all the research subjects to participate in a voluntary and anonymous manner. At the time of the interview, we provided them with information on the study and some directions for its implementation. All subjects signed a privacy consent form.

\section{Analyses}

We analyzed the interviews by means of reiterated and interactive phases of reading and codifying the material in keeping with guidelines on analyses set forth by the grounded theory method (Strauss \& Corbin, 1998; Tarozzi, 2008).
In accordance with the analyses, we identified four core categories: motivations, relations with organization, effects of volunteerism (in terms of civic engagement and identity construction), and family. We then interpreted the core categories using the literature on volunteerism.

We crafted the interview grid in order to identify these four principal macrocategories:

- Motivations: In this category the types of motivations that volunteers and exvolunteers stated as being at the basis of their choice to become involved were considered. We categorized the motivations according to Omoto and Snyder's (1995) classification (self-protection, development of social relations, career, understanding, self-enhancement) and subsequently we re-categorized them into self-oriented and other-oriented motivations. We then investigated how individuals' motivations were combined with respect to the choice to begin and, especially, to sustain voluntary activity, and how and for which reasons they evolved over time. Moreover, we investigated whether the choice to enter and become involved in volunteerism was personal or could be attributed to the intervention of significant individuals in the young person's life.

- Organization: The macrocategory concerns the relationship with the association where the most significant experience of volunteerism occurred. According to Omoto and Snyder's model (1995), focus was on the categories of integration in the organization and identification with it, as well as on the satisfaction deriving from the act of volunteering, from belonging to the organization in a broad sense, and from the relationship with the organization and other volunteers.

- Identity: The category that we examined was social identity deriving from belonging to the volunteer organization and, especially, the role identity deriving from the act of volunteering. In particular, referring to Piliavin and Siegl's work (2007), we examined the processes of development, or lack thereof, of social identity connected to volunteerism, 
the development of the role identity of a volunteer, and the resulting changes attributable to involvement in volunteerism.

- Family: The category of analysis was the family environment as the place in which the young adult has grown up and matured and was, or was not, brought up to prosociality, supported in his or her prosocial choices and social commitments, and exposed to parental models of social commitment and citizenship. In keeping with the relationalsymbolic approach of Scabini and Cigoli (2000), we considered the data related to personality formation and propensity to volunteer, family-transmitted values, parental support, and presence or absence of prosocial behaviors and/or attitudes in parents.

Each interview was read and coded by two psychologists on the work team, who carried out the role of independent judges. Inter-rates accord was high (between 0.80 and 0.85).

\section{Results}

From the analysis of the in-depth interviews conducted in order to understand why young people decide to continue to volunteer over an extended period of time and why some of them decide to stop/interrupt their commitment, we identified four different groups. Two of them were with respect to volunteers still in service:

- Volunteers in continuous "training": producers of active citizenship

- Volunteers for reasons of "personal necessity"

The other two were with respect to exvolunteers:

- Ex-volunteers "witnesses" for solidarity and active citizenship

- Ex-volunteers "by chance"

\section{Volunteers in Continuous "Training": Producers of Active Citizenship}

The first typology, Volunteers in continuous "training" (producers of active citizenship) represents $42.1 \%$ of participants. This typology is constituted by volunteers who acknowledge that the experience of volunteerism plays a crucial role in their identity construction. Many of the young people who belong to this group participate in voluntary action as a personal choice.

Satisfaction and self enhancement aspects, determined by experience and interpersonal relationships, are acknowledged as principal motivations at the basis of the choice to continue voluntary activity; in the same way, however, there is a recognition of value motivations and generative aspects, understood as the assumption of responsibility for caring for the needy in virtue of a generative model learned in the family.

The element that characterizes this group is the conscious awareness that their motivations have matured thanks to the experience of volunteerism:

... at the same time that I was growing as a person, in age and in responsibilities, I didn't do volunteer work only in a concrete way but I also thought about $i t$... reflecting on volunteerism, on motivations... (Interview 212$)^{1}$

The relational dimension plays an important role in keeping commitment alive:

... you start with the idea of giving, instead you receive... even now when they ask me why I put all that time into it, I answer that it's because I couldn't do without it. (Interview 273)

As in the case of motivations, personal social action likewise evolves over time: The changes caused by the passage to adulthood limit the time available to carry out direct volunteer activity. These subjects, who over time have developed a strong identification with the association, choose to continue to provide structural support while modifying their role, moving from giving beneficiaries direct aid to the unpaid and voluntary role of coordination in the organization.

The bond with the organization is also determined by relations of friendship and mutual respect with other volunteers who are participating in the activity.

\footnotetext{
1 Quotation drawn from interview 212. Other quotations will follow indicating the interview from which they were drawn.
} 
At a personal level, the subjects in this group recognize that voluntary service plays an important role in their identity construction; it is a privileged space in which they can express themselves and grow:

... by being with them I understood a lot of things about myself, a lot of things that I experienced before and that I had a hard time accepting... and I resolved them... this experience allowed me to mature and enrich myself... I have a better understanding of what I am... I give, I receive, and whatever $I$ received and that helped me to become a better person, I give it back for other people to use... (Interview 267)

The path of upbringing and growth developed in their family contexts creates a cultural background that promotes the intention to dedicate part of their time to helping others, inducing them to give time and energy to society and to its neediest members:

... it seems natural to me that maybe it comes from the fact of being such a big family, we were used to sharing, to doing things without getting anything in return, without asking why do I have to do this... it seems to me to be something we owe... because you have so many opportunities, it seems right that you give back what you received... (Interview 273)

The family stands as the first agency that through its childrearing function is able to orient children towards making a conscious choice to help others. Often this choice is shared by the rest of the family and is consequently supported by a perspective of generativity which becomes social, when it passes from caring for one's own children to caring for society.

In brief, volunteerism for these subjects is a source of satisfaction and personal enhancement, as well as the opportunity to put into practice values and prosocial norms: These are young people moved to volunteer by both altruistic and instrumental motivations with clear generative connotations. The relationships created within the organization and the support received from it have allowed them to feel part of a new social network outside their family of origin, to relate to people who differ from them in suffering and hardship, but also to be able to contribute for the first time to others' wellbeing. Many of them state explicitly a choice and desire to transmit to others the values interiorized in their own process of growth by means of voluntary service in the organization. This represents adhering to a life style, a life project, which these young people have assimilated over time, sharing ideals, norms, and rules.

\section{Volunteers for Reasons of "Personal Necessity"}

The second typology, represented by Volunteers for reasons of "personal necessity"(7.9\%), sees volunteerism as a means to fulfil personal demands and needs without being able to also develop motivations of a more prosocial nature. One has the impression that these young people continue to engage in voluntary service as if they were in search of and waiting for something or someone to help them look beyond their own difficulties and personal history, to broaden their family horizons and build an autonomous adult identity.

The predominant motivations in participants of this typology have to do with a desire for relationship and personal enhancement in terms of training and career. Volunteerism comes to be seen as an activity like any other, an unpaid job that challenges one's theoretical competencies:

... I feel useful and competent in this context... I don't notice a missionary motivation... to do good... It's a preparation for work... Even though I didn't get paid, I would have worked the same as if it were a job... (Interview 84)

Voluntary activity thus has the task of putting into practice and making concrete theoretical competencies acquired in school, experimenting with the assumption of responsibility. It becomes a learning experience in which the search for and experimentation with one's personal and professional role become clear.

Since the aspect of personal growth is emphasized, these young people do not believe that they have developed significant bonds with the other volunteers. 
The relationship with the organization is seen in this group to be highly compromised: We find, in fact, situations in which this relationship is complicated and not always manageable, both due to a lack of good will on the part of volunteers and to the difficulty in reading their only partly defined motivations.

In the absence of a supportive family network that spurs children toward prosocial action and lacking solid underlying motivations for the choice to volunteer, as well as significant relations with other volunteers and the organization, it is intuitive to conclude that these subjects do not register any modifications to identity due to involvement in the volunteer organization.

The interviewees belonging to this group have in common complicated family situations: In some cases a family member is ill or has died, or there are economic difficulties. In any case, there are events around which the entire family life revolves, due to which it inevitably assumes a self-referential and minimally generative modality.

In this type of family context, even the choice to begin voluntary activity turns out to be tied to mostly undefined motivations and often to an unacknowledged search for a sense of oneself.

In brief, volunteerism is, in this case, a way to learn to face and manage problems without reflecting on the effects of this involvement and on its true underlying motivations:

... it's not help that you give... it's a way to put yourself out there... if it helps someone, all the better... if not,... it's not too bad... when you have an idea it's better to express it and put it into practice, then, if it's good, the people who use it will decide... (Interview 218)

\section{Ex-Volunteers “Witnesses"forSolidarity and Active Citizenship}

The third typology is represented by ExVolunteers "witnesses" for solidarity and active citizenship (29.1\%). Like the volunteers in continuous training, this group ascribes to a form of volunteerism undertaken due to personal motivations that were subsequently also enriched with prosocial mo- tivations: The latter thus come to play an important role in the volunteers' personal growth. Despite having had a positive experience as volunteers, these subjects quit their involvement mostly due to time constraints following structural changes, such as beginning a new job, marriage, or the birth of a child.

In this typology, the initial incentive to volunteer is determined above all by subjects' relational roots through which they are initiated into the world of volunteerism, thanks to meeting and being influenced by significant people, especially in their social network (teachers, priests). Another factor that influences commitment to voluntary service is a positive experience in the organization and a group of friends that carries out an attractive function in motivating people to participate in voluntary activity:

... the daughter of a friend of my mom's... she was in an organization so she had already been doing it... She's a very lively person, very talkative, she immediately connects with everybody...

I don't know if that's what pushed me to say, yes, I'll try it... (Interview 242)

The relation among the volunteers is so positive that it becomes true friendship. In fact, the organizational dimension carries out the social function of providing opportunities to meet other people with whom one can establish friendships by sharing a common goal:

... we grew together by living the same experiences... a similar path on which friendship goes beyond service... (Interview 268)

The positive experience in the organization has oriented the process of identity construction in these young people: Social action has made possible interaction and communication with people other than themselves, developing capacities to accept themselves and others through a participatory interchange. In this group the majority of interviewees developed a transcendent view of their reality, that is, a greater awareness of themselves and their own condition, as well as of others, especially those suffering hardships, with an active commitment to producing social change. In all 
these young people volunteerism has left a positive mark: The experience of volunteering has made them witnesses for solidarity and active citizenship and has allowed them to translate into concrete action the generative force that one notices in their attitudes, thoughts, and ideals.

The subjects in this typology describe their families in very positive terms, as united and rooted in values of respect and dialogue. Often the parents in these families work or have worked in volunteerism, thus transmitting it to their children as an enriching and important experience. These are families that transmit values of dialogue within and outside of the family, of the pleasure of being with others, of taking care of one's own and other's needs, and of respect for others and especially for people experiencing difficulties:

... I learned about respect by seeing them... I've always seen in them respect for others, getting involved... so I absorbed it the same way... (Interview 102)

In brief, all these subjects were raised in generative and prosocial families that model and transmit the values of solidarity and commitment. Moreover, the volunteer organization plays for them a supportive role that helps them read their experience in a new light and interpret it partly as a result of initial training courses that provide the bases for managing and facing the diverse and critical moments of their experience.

One of the feelings that emerges and is connected to collective motivations is the need for affiliation in the volunteer group and the need to belong to a collectivity. Both are as important as personal dimensions.

\section{Ex-Volunteers "by Chance"}

The fourth typology is represented by Ex-Volunteers "by chance" (20.9\%), who reveal themselves to be "impervious" to experiences: They do not recognize an incisive role for voluntary action in their personal growth. The experience of volunteerism is undertaken by chance. The initial incentive to engage in voluntary activity did not originate in family or cultural roots; rather, the decision to actively participate in a voluntary association as a volunteer is characterized by a more individualistic, sometimes utilitarian, approach in which the experience is undertaken as an opportunity to socialize, experiment with skills, and receive gratification:

... it was a difficult period and I couldn't
accomplish anything... I needed to give
myself over to something... it was a
challenge for me... I threw myself into
it to test myself, because I felt I needed
to see how you face pain, by sharing and
managing it... (Interview 5)

Motivations in all the subjects remained stable over time and were primarily connected to the egotistical and instrumental aspect of volunteering:

... wanting to do something for others to

feel better about yourself... (Interview 64)

The organization is only a place where they can be challenged and satisfy emotional and personal needs.

These young people offer a critical view of the organization, "accusing" it of not supporting the volunteers, of not offering enough spaces for discussion and dialogue in order to deal with difficult moments in the helping relationship. In particular, the presence of paid staff in the association generates conflicts and tensions due to their different position and the way beneficiaries are handled, both in training methods and the way volunteers are managed and involved. Often the subjects in this typology complain that the organizations do not pay enough attention to volunteer selection: With the sole aim of having a sufficient number of people to provide services, people are accepted who are not particularly motivated or suitable for carrying out specific requested activities. All the subjects acknowledge difficulties in relating to the beneficiaries of their service. Despite the training provided by the organization, the volunteers often found themselves unable to put into practice what they had learned, unable to help, experiencing a sense of frustration and helplessness:

I felt lost faced with this aggressiveness that I didn't know how to manage... (Interview 37) 
These are young people who are experiencing serious difficulties and are unable to re-elaborate either the motivational path that led them to become involved in the world of volunteerism, any related expectations, or the effects of prosocial action.

The families in this group do not seem to have the capacity to influence their children's choices or to provide a model with which to identify in a positive fashion. These families are somehow not entirely present; they are seemingly peaceful but are possessed by a complexity that is not always apparent or easy to face:

My family is like a nice picture, they always have the image of being a perfect family, even if in reality it isn't like that at all. (Interview 21)

In brief, for these young people the decision to end voluntary activity is determined by lack of time, due either to changes in family life or work; however, unlike the preceding group, these subjects have had experiences that were quite difficult to manage on a relational level within the organization, such that none of them attribute to their voluntary experience an incisive role in their personal growth:

... it was useful to me in that moment but it didn't change my life... (Interview 21)

\section{Discussion and Conclusions}

In conclusion, in this investigation we identified four typologies of volunteers and ex-volunteers determined by the areas examined: motivations, relationships with the organization, effects of volunteerism on life and identity, quality of family relationships. For subjects who decided to sustain voluntary involvement, the two typologies that we identified are Volunteers in continuous "training" and Volunteers for reasons of "personal necessity". When the decision was to quit the activity, the two typologies that emerged are Ex-Volunteers "witnesses" for solidarity and active citizenship and Ex-Volunteers "by chance".

Overall, with respect to the examined areas, what do the four typologies illustrated in detail in the preceding paragraphs tell us about the commitment of young people to volunteerism and civic engagement?
Through volunteerism some volunteers experienced themselves as being part of a collective force and making significant contributions to improving the situation of others. Volunteerism seems to be how they choose to develop civic engagement.

On the other hand, some ex-volunteers think that the world of helping is an illusion, a manipulative world. These young adults "refuse" to establish any bond either with the organization or with other volunteers. They express anger and resentment towards volunteerism and the organization.

In contrast, some other ex-volunteers recognize that volunteering represented an important step in their life and helped them to grow, especially from a civic point of view. We can say that for them volunteerism seems to have framed the process of civic development in a positive way, so that now they are active citizens. They were satisfied with the organization and well integrated; they are still in contact with it and experience positive feelings and gratitude towards it.

In accordance with Omoto and Snyder (1995) and Chacón et al., (2006), we can affirm that satisfaction with the organization is among the determining factors, not only of the choice to abandon voluntary activity, but also of the effects of the experience itself.

Referring to Grube and Piliavin (2000), we can conclude that in the group of participants under investigation the evolution of initial motivations towards a redefinition of role identity (with effects on identity and active citizenship) was at the basis of sustained involvement over time, guaranteeing, even when activity was interrupted for some reason, a certain stability in the reported changes.

Finally, turning to the aspect of the family, which we saw as being central, it is possible to say that correspondences exist between the four typologies of volunteers and ex-volunteers and family configurations that, in some cases, encourage generativity, while in other cases they inhibit it. In effect, although modalities differ, the families of young people who have carried out or are carrying out voluntary activities have encouraged or supported this choice in their young people. Particularly, those in the first typology seem able to not 
only be fully generative and to transmit a set of values characterized by solidarity, prosociality, and sharing, but also to give the new generation space to say something new, to interpret autonomously, in its own time and its own way, what it has received from the preceding generation (Flanagan \& Faison, 2001). These are families who seem to corroborate Scabini and Cigoli (2000) in the relational-symbolic approach: Experiencing these values in the family promotes the transfer of primary family capital in the community, transforming it and promoting the production of secondary social capital.

The available findings allow us to agree with McAdams (2006) in that generative parents today have the task of promoting and transmitting generativity and its associated values while balancing traditional aspects of their own generation and adult role with innovative aspects brought by new generations.

Despite the convergence in the results we obtained and the consistency between our findings and the theoretical analysis we developed, there are some limitations that could be addressed in future research. In the first place, the volunteers of the present study are young people involved in a particular type of volunteerism: related to youth and children. It would be interesting to know if these results can be extended to young people engaged in other areas of volunteerism.

Secondly, the study only takes into account the voices of the volunteers; it would be interesting to also have the point of view of the organizations and other volunteers with reference to the path taken by this young people's involvement.

From the methodological standpoint, the research design allowed us to deepen and develop empirical evidence that until now has been investigated for the most part in quantitative terms, highlighting the complexity of the themes under study and making it possible to better understand their implications, that is, the meaning of voluntary action taken by young people. It would have been interesting to also propose to subjects a semi-projective instrument, such as the Family Live Space or the Thematic Apperception Test, in order to also examine more in depth the less aware level of these young people's stories, especially of those who belong to typology of Ex-Volunteers by chance and who seem to live in a situation of difficulty and suffering.

These limitations take the form of stimuli for future research into these themes.

Finally, the work we presented has important implications for volunteer organizations with respect to recruitment and retention of volunteers. Understanding which motivations accompany the decision of young people to volunteer, and helping them reflect on these motivations, is extremely important both for volunteer retention and for grasping the type of training they need. Moreover, an understanding of the true demands made on the organization by young people (affiliation, social parenting, belonging, an almost therapeutic request for help) can help organizations to do a better job in selecting young people, matching volunteers with beneficiaries of the service, and identifying the type of service that can best promote in the young volunteer the maturation of civic identity and an awareness of the significance of volunteerism.

These findings provide further corroboration of Penner (2002) when he writes: "Service organizations must do more than simply recruit volunteers; they must work to maximize the volunteer's involvement with the organization" (p. 464).

We can conclude by saying that volunteerism may represent an arena in which it is possible to experiment with citizenship. Sometimes it leaves a trace of this in young persons' identity, causing them, even if they quit, to feel part of something bigger than him or herself that is worthy of commitment; at other times, when the experience does not become rooted in the self, it seems to leave no mark at all.

\section{References}

Barbaranelli C., Caprara G. V., Capanna C., \& Imbimbo A. (2003). Le ragioni del volontariato: un contributo empirico [The reasons of volunteerism: An empirical contribution]. Giornale Italiano di Psicologia, 2, 369-388. doi:10.1421/8919

Boccacin, L. \& Marta, E. (Eds.) (2003). Giovaniadulti, famiglia e volontariato: percorsi di costruzione dell'identità [Young adults, family and volunteering: Course of the construction of identity]. Milano, Italy: Unicopli. 
Bruscaglioni, M. (1997). La gestione dei processi nella formazione degli adulti [The management of the processes in the training of adults]. Milano, Italy: Franco Angeli.

Callero, P. L., Howard, J. A., \& Piliavin, J. A. (1987). Helping behaviour as a role behaviour: Disclosing social structure and history on the analysis of prosocial action. Social Psychology Quarterly, 50, 247-256.

Chacón, F., Menard, M., Sanz, M., \& Vecina, M. L. (1998). Psychosocial factors that influence volunteer work: A pilot study. Psychology in Spain, 2, 108-115.

Chacón, F., Vecina, M. L., \& Davila, M. (2006, June). The three stage model of volunteers' duration of service. Paper presented at the Society for the Psychological Study of Social Issues Biennial Meeting, Long Beach, CA.

Clary, E. G. \& Miller, J. (1986). Socialization and situational influences on sustained altruism. Child Development, 57, 1358-1369.

Clary, E. G., Snyder, M., Ridge, R. D., Copeland, J., Stukas, A. A., Haugen, J., \& Miene, P. (1998). Understanding and assessing the motivation of volunteers: A functional approach. Journal of Personality and Social Psychology, 74, 1516-1530. doi:10.1037/0022-3514.74.6.1516

Clary, E. G., Snyder, M., \& Worth, K. (2003). The volunteer organization environment: Key dimensions and distinctions. Washington, DC: Aspen Institute, Nonprofit Sector Research Fund.

Eisenberg, N. \& Fabes, R. A. (1998). Prosocial development. In W. Damon, N. Eisenberg (Eds.), Handbook of child psychology, Vol. 3: Social, emotional and personality development $\left(5^{\text {th }}\right.$ ed., pp. 771-778). Hoboken, NJ: John Wiley \& Sons.

Erikson, E. H. (1968). Identity. youth and crisis. New York, NY: Norton.

Flanagan, C. A. \& Faison, N. (2001). Youth civic development: Implications of research for social policy and programs. Social Policy Report, 15(1), 3-14.

Fletcher, C., Elder, G. H. J., \& Mekos, D. (2000). Parental influences on adolescent involvement in community activities. Journal of Research on Adolescence, 10, 29-48.

Grube, J. A. \& Piliavin, J. A. (2000). Role identity, organizational experiences, and volunteer performance. Personality and Social Psychology Bulletin, 26, 1108-1119. doi:10.1177/0146167200 2611007

Hart, D. \& Fegley, S. (1995). Prosocial behavior and caring in adolescence: Relations to selfunderstanding and social judgment. Child Development, 66, 1346-1359. doi:10.1111/j.14678624.1995.tb00939.x

Marta, E. \& Pozzi, M. (2007). Psicologia del volontariato [Psicología del voluntariado]. Roma, Italy: Carocci.

Marta, E. \& Scabini, E. (2003). Giovani volontari: impegnarsi, crescere e far crescere [Young volunteers: Commit themselves, grow and let grow]. Firenze, Italy: Giunti.

McAdams, D. P. (2006). The redemptive self. Oxford, United Kingdom: Oxford University Press.
McAdams, D. P. \& de St. Aubin, E. (1992). A theory of generativity and its assessment through selfreport, behavioral acts, and narrative themes in autobiography. Journal of Personality and Social Psychology, 62, 1003-1015. doi:10.1037/00223514.62.6.1003

McCall, G. \& Simmons, J. L. (1978). Identities and interactions. New York, NY: Free Press.

Omoto, A. M. \& Snyder, M. (1993). AIDS volunteers and their motivations: Theoretical issues and practical concerns. Nonprofit Management \& Leadership, 4, 157-176. doi:10.1002/nml.4130040204

Omoto, A. M. \& Snyder, M. (1995). Sustained helping without obligation: Motivation, longevity of service, and perceived attitude change among AIDS volunteers. Journal of Personality and Social Psychology, 68, 671-686. doi:10.1037/00223514.68.4.671

Penner, L. A. (2002). Dispositional and organizational influences on sustained volunteerism: An interactionist perspective. Journal of Social Issues, 58, 447-467. doi:10.1111/1540-4560.00270

Piliavin, J. A., Grube, J. A., \& Callero, P. L. (2002). Role as resource for action in public service. Journal of Social Issues, 58, 469-485. doi:10.1111/0022-4537. t01-1-00027

Piliavin, J. A. \& Siegl, E. (2007). Health and benefits of volunteering in the Wisconsin longitudinal study. Journal of Health and Social Behavior, 48, 450464. doi:10.1177/002214650704800408

Pozzi, M. \& Marta, E. (2006). Determinanti psicosociali del volontariato durante la transizione all'età adulta [Psychosocial determinant of volunteering in the transition to adulthood]. Psicologia Sociale, 1, 175-196.

Puddifoot, J. E. (1996). Some initial consideration in the measurement of community identity. Journal of Community Psychology, 24, 327-336. doi:10.1002/(SICI)1520-6629(199610)

Scabini, E. \& Cigoli, V. (2000). Il famigliare [The family]. Milano, Italy: Raffaello Cortina.

Singer, J. A., King, L. A., Green, M. C., \& Barr, S. C. (2002). Personal identity and civic responsibility: "Rising to the occasion" narratives and generativity in community action student interns. Journal of Social Issues, 58, 535-556. doi:10.1111/15404560.00275

Snyder, M. \& Omoto, A. M. (2000). Doing good for self and society: Volunteerism and the psychology of citizen participation. In M. Van Vugt, M. Snyder, T. R. Tyler, \& A. Biel (Eds.), Cooperation in modern society: Promoting the welfare of communities, states and organizations (pp. 127141). New York, NY: Routledge.

Strauss, A. \& Corbin, J. (1998). Basics of qualitative research: Techniques and procedures for developing grounded theory ( $2^{\text {nd }}$ ed.). Newbury Park, CA: Sage.

Tarozzi, M. (2008). Che cos’è la grounded theory [¿What grounded theory is?]. Roma, Italy: Carocci.

Wilson, J. (2005). Some things social surveys don't tell us about volunteering. In A. M. Omoto (Ed.), Processes of community change and social action (The Claremont Symposium on Applied Social Psychology, pp. 29-50). Mahwah, NJ: Lawrence Erlbaum. 